\title{
3D Cellular Imaging Using Time-of-Flight Secondary Ion Mass Spectrometry
}

\author{
M. Robinson,* J. Brison,* D.G. Castner,* \\ * National ESCA and Surface Analysis Center For Biomedical Problems, Departments of Chemical Engineering and \\ Bioengineering, Box 351750, University of Washington, Seattle, WA 98195.
}

Time-of-flight secondary ion mass spectrometry (ToF-SIMS) is a powerful surface analysis technique that is increasingly being used to image biological tissues and cells [1,2]. High chemical specificity, along with submicron lateral and depth resolution makes ToF-SIMS imaging a great complement to other imaging techniques used in the life sciences. A key factor is sample preparation. An ideal protocol is one that keeps the cell as close to its living state as possible, even when introduced into the harsh, ultra-high vacuum environment required for ToF-SIMS analysis. In this work multiple sample preparation protocols are investigated to determine which provides the best approach for 2D and 3D imaging of single cells. Various cell types were prepared by: rinsing in $0.15 \mathrm{M}$ ammonium acetate, flash freezing in liquid ethane, and then imaging them in either a freeze-dried or a frozen hydrated state. The ToF-SIMS images obtained with these methods were compared to images created after chemical fixation of the cells with paraformaldehyde. The frozen hydrated sample preparation technique better maintains the cell's native chemical and morphological state, providing the most useful information. However, freeze-drying does maintain some structural integrity of the cell. Additionally, freeze-fractured samples were also analyzed in the freeze-dried or frozen hydrated states and compared. 5-bromodeoxyuridine (BrdU) was incorporated into the cell nucleus and used to help determine the location of fracture plane in the cell.

ToF-SIMS experiments were performed using an ION-TOF TOF.SIMS 5-100 (ION-TOF GmbH, Münster, Germany). 3D secondary ion images were collected in the dual beam mode (imaging alternating with etching). Images with submicron lateral resolution were acquired by rastering a pulsed $25 \mathrm{keV} \mathrm{Bi3}+$ beam across the sample surface. Etching was done with a $10 \mathrm{keV} \mathrm{C60+} \mathrm{beam} \mathrm{to} \mathrm{minimize} \mathrm{damage} \mathrm{in} \mathrm{the} \mathrm{etched} \mathrm{sample.} \mathrm{NIH} \mathrm{3T3} \mathrm{mouse}$ fibroblasts were maintained in Dulbecco's minimum essential medium (Invitrogen) containing high glucose, sodium pyruvate and L-glutamine, and supplemented with 10\% fetal bovine serum (Hyclone) at $37^{\circ} \mathrm{C}$ and $5 \% \mathrm{CO} 2.104$ cells were seeded onto $1 \mathrm{~cm} 2$ polished silicon and allowed to grow to $60-70 \%$ confluence, usually taking 48 hours. For rinsing experiments a $150 \mathrm{mM}$ ammonium acetate (AA) solution was prepared immediately prior to rinsing, and brought to $\mathrm{pH} 7.4$ with $1 \mathrm{M} \mathrm{NH} 4 \mathrm{OH}$. Freeze-drying occurred for 24 or 48 hours. Freeze fracture experiments were performed using the method described by Chandra and Morrison [3]. Briefly, cells are grown on a silicon substrate; 10 micron polystyrene beads are added to the media and allowed to settle. A second silicon piece is place on top forming a "sandwich" with the cells, media and beads in the middle. The entire sandwich is flash-frozen in liquid ethane, transferred to liquid nitrogen, and separated under liquid nitrogen creating a fracture plane somewhere through the middle of the sandwich. Figure 1 shows a sample rinsed for 30 seconds with AA and subsequently freeze-dried. Images A-C are the $\mathrm{K}+$ signal at $\mathrm{m} / \mathrm{z} 39$, while images $\mathrm{D}-\mathrm{F}$ are the lipid fragment $\mathrm{C} 5 \mathrm{H} 12 \mathrm{~N}+$ signal at $\mathrm{m} / \mathrm{z}$ 86. Images $1 \mathrm{~A}$ and $1 \mathrm{D}$ were acquired before any sputtering with $\mathrm{C} 60+$. Images $1 \mathrm{~B}$ and $1 \mathrm{E}$ were acquired after 500 seconds of $\mathrm{C} 60+$ sputtering at $0.45 \mathrm{nA}$ current using a 500 micron $\mathrm{x} 500$ micron raster area. Images $1 \mathrm{C}$ and $1 \mathrm{~F}$ were acquired are after 1750 seconds of $\mathrm{C} 60+$ sputter. There are significant changes in the lipid signal as the cell is sputtered. In image 1D, the lipid signal covers the entire cell, as expected, but individual cells are difficult to discern. By image 1F, individual cells are clearly visible, and the lipid signal is confined to the periphery of individual cells. In images $1 \mathrm{~A}-1 \mathrm{C}$ the $\mathrm{K}+$ signal is distributed evenly throughout the cells, but the etching away of the cytoplasm is clear. A series of these XY-images, acquired as a function of sputter time, can be stacked to form a $3 \mathrm{D}$ image. Figure 2 presents images from a freeze-fractured, freeze-dried cell sample. The chemical integrity of the cells are maintained, as is evident by the high $\mathrm{K} / \mathrm{Na}$ ratio seen in $2 \mathrm{~A}$ and $2 \mathrm{~B}$ [3]. It is also evident that the fracture plane passes through the cell. SEM images taken of the same area (not shown) show the fractured areas are smooth, as expected. Several different sample preparation protocols for ToF-SIMS imaging of cells have been examined. The evolution of the K, $\mathrm{Na}$ and lipid signals as a function of $\mathrm{C} 60$ sputter time have been followed. C60 sputtering is 
a promising method for removing surface contamination as well as profiling through cells. Frozen-hydrated analysis should cause less damage to the cells than freeze-drying, thus providing more relevant results for both rinsed and fractured samples. It can be seen however, that freeze-drying a sample can maintain the K/Na integrity of the cell, thus it is able to provide some accurate information. Analyzing frozen-hydrated samples is a challenging endeavor, so it is also to develop other more straightforward sample preparation methods that also can provide relevant information about key species in cells.

[1] Winograd N, Anal. Chem.77 (2005) 143A

[2] Chandra S, Anal. Chem. 72 (2000) 104A

[3] Chandra S, J. Microsc. 144 (1986) 15-37

[4] This research was supported by the National Institutes of Health grant \#EB-002027. The aid of Winston Ciridon, Chris Barnes and Shin Muramoto is gratefully acknowledged.

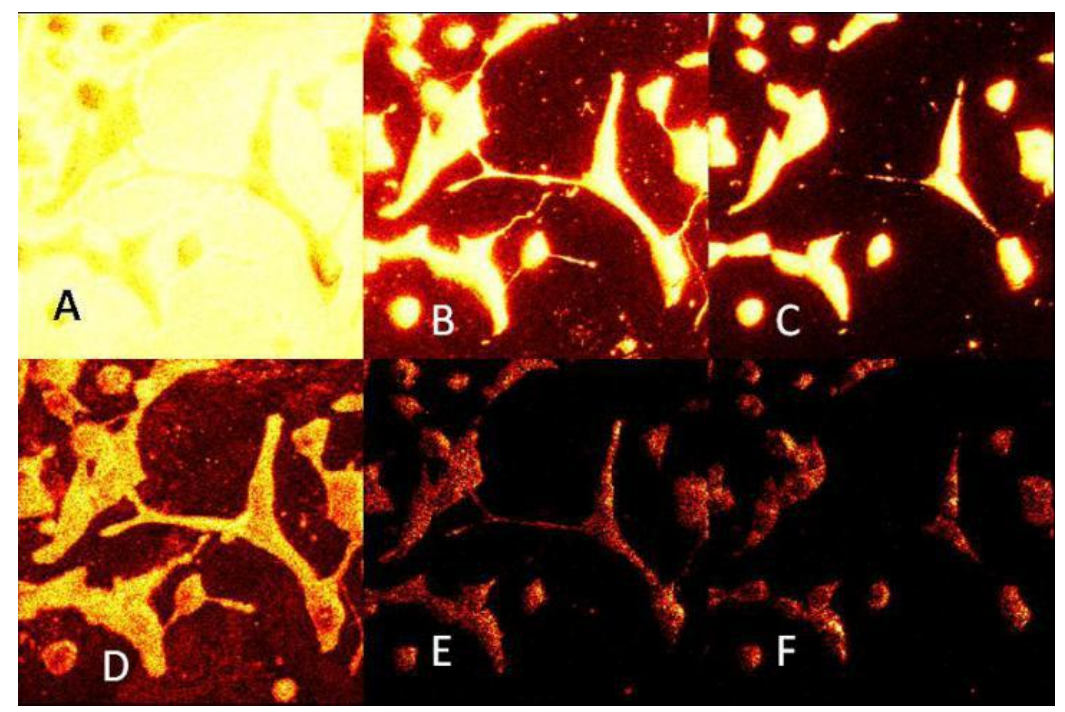

FIG.1. Left block of images. All images 246x246 microns. A-C is the $\mathrm{K}+$ signal at $\mathrm{m} / \mathrm{z} 39$ after 0,500 and 1750 seconds sputter with $0.45 \mathrm{nA} \mathrm{C} 60+$. D-F is the lipid fragment $\mathrm{C} 5 \mathrm{H} 12 \mathrm{~N}+$ at $\mathrm{m} / \mathrm{z} 86$ at 0,500 and 1750 seconds sputter with $0.45 \mathrm{nA} \mathrm{C} 60+$.

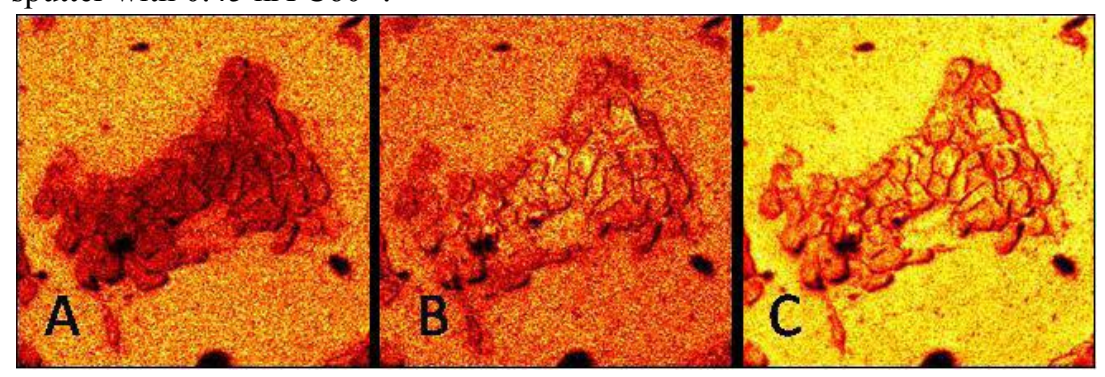

FIG. 2. Right block of images. All images $347 \times 347$ microns. Freeze-dried fracture of a group of fibroblasts. A is the $\mathrm{Na}+$ signal at $\mathrm{m} / \mathrm{z} 23$, B is the $\mathrm{K}+$ signal at $\mathrm{m} / \mathrm{z} 39$, and $\mathrm{C}$ is the total ion signal. 